\title{
Sexual behaviours and condom use among young urban women in a town in northeast India: Implications for prevention and control of sexually transmitted infections
}

\author{
Bichitrani Marak ${ }^{a, b}$, Tarun Bhatnagar ${ }^{a, *}$ \\ ${ }^{a}$ ICMR School of Public Health, National Institute of Epidemiology, Indian Council of Medical Research, Chennai, India \\ ${ }^{\mathrm{b}}$ Sub-divisional Medical and Health Officer, Baghmara, South Garo Hills, Meghalaya, India
}

\section{A R T I C L E I N F O}

Article history:

Received 15 September 2015

Accepted 6 November 2015

Available online 27 November 2015

Keywords:

Anal sex

C-ACASI

HIV

Pre-marital sex

Sexual debut

\begin{abstract}
A B S T R A C T
Background/objectives: Young women are more vulnerable to sexually transmitted infections (STIs). Our objectives were to estimate the prevalence of sexual behaviours and condom use by types of partner, and determine the factors associated with condom use during last sex among 18-24-year-old young women of Tura town in Meghalaya.

Methods: We did a cross-sectional survey among 250 young women using colour-coded audio computer assisted self-interview system for data collection. Multiple logistic regression analysis was used to estimate adjusted odds ratio to determine the factors independently associated with condom use.

Results: Ever having sex was reported by $61 \%$ women. In all, $20 \%$ were married, and $18 \%$ had a boyfriend. Pre-marital sex was reported by $54 \%$ women. Thirteen percent of 92 women reported ever practicing anal sex. Prevalence of condom use during last sex was $32 \%$ with husband and 38\% with boyfriend. Age between 18 and 20 years, students, teachers, and knowledge on HIV prevention were significantly associated with condom use during last sex with husband.

Conclusions: Young urban women in this area need comprehensive sexual education and awareness on modes of transmission of STIs, including HIV. Prevention messages targeting young individuals should include information on risk of early sexual debut, pre-marital sex, and unsafe sex.
\end{abstract}

(C) 2015 INDIACLEN. Published by Elsevier, a division of Reed Elsevier India, Pvt. Ltd. All rights reserved.

\section{Introduction}

Globally about 340 million new cases of four main curable sexually transmitted infections (STIs), i.e., gonorrhoea, chlamydia, syphilis, and trichomoniasis, occur every year in men and women aged between 15 and 49 years, ${ }^{1}$ with $75-85 \%$ occurring in developing countries and nearly half among young people aged 18-24 years. Young women, aged 18-24 years, had highest rate of STIs as compared to any other age

\footnotetext{
* Corresponding author at: ICMR School of Public Health, National Institute of Epidemiology, Indian Council of Medical Research, R-127, Tamil Nadu Housing Board, Ayapakkam, Chennai 600077, India. Tel.: +91 44 26136211; fax: +91 4426136426.

E-mail addresses: mph5cbchm@gmail.com (B. Marak), tarunbhatnagar@nie.gov.in (T. Bhatnagar).

http://dx.doi.org/10.1016/j.cegh.2015.11.002

2213-3984/C 2015 INDIACLEN. Published by Elsevier, a division of Reed Elsevier India, Pvt. Ltd. All rights reserved.
} 
and sex. ${ }^{2}$ Women are more vulnerable to STIs due to biological and social factors, including less negotiating power for sex, economic dependence, less education and different sociocultural norms for men and women. ${ }^{3}$

Early initiation of sexual intercourse and more number of sexual partners indicate risky behaviour. ${ }^{4}$ Entry into sexual life at a younger age has been considered to lead to higher reporting of sign and symptoms of genital infection in young women than men. Whether forced ${ }^{5} /$ (unwanted) or otherwise, most of the young women here are often vulnerable to unsafe sexual intercourse. Although condoms prevent unintended pregnancy and STIs including HIV, their use remains inconsistent. The greatest responsibility for safe sex is placed on women due to possible consequences of unprotected sex being generally more serious in them than in men.

The reported prevalence of STIs and reproductive tract infections (RTI) among adults is 19\% in Meghalaya state of India and $25 \%$ in West Garo Hills district of Meghalaya. ${ }^{6}$ According to recent evaluation of STI/RTI prevention and management programme, $42 \%$ of STI cases attending District Hospital STI Clinic in Tura town of West Garo Hills were among 18-24-year-old females. ${ }^{7}$ In Meghalaya, women are the decision makers regarding health and sexual matters. ${ }^{8}$ Further, knowing the usage pattern of condoms among women can be useful to foster the development of programme for the promotion of condom use. However, there are no data available on sexual behaviour and of condom use, in Tura town. We conducted this study to describe the sexual behaviour among young female adult aged 18-24 years in Tura, estimate the prevalence of condom use and determine the factors associated with condom use among them.

\section{Methods}

\subsection{Study design and setting}

We conducted a cross-sectional survey in Tura town, district headquarters of West Garo Hills in Meghalaya, from January to March, 2014. The population of West Garo hills is $6,42,923$, and the population of Tura is 75,078 with $80 \%$ scheduled tribes. The average female literacy rate is $90.27 \%{ }^{9}$

\subsection{Sampling and sample size}

Assuming the proportion of women, who ever had sex to be $22 \%,{ }^{8}$ relative precision $5.5 \%, 95 \%$ confidence interval (CI) and $20 \%$ non-response; we calculated the sample size to be 250 . We used a table of random numbers to select 250 young females aged 18-24 years from the 2013 electoral list of 3600 women in Tura town. Those not available at the time of survey were replaced by another participant randomly selected from the electoral list until the sample size of 250 was achieved.

\subsection{Data collection}

We used color-coded audio computer assisted self-interview (C-ACASI) system for data collection. ${ }^{10}$ Data were collected using a structured questionnaire including items related to socio-demographic characteristics, numbers and types of sexual partners (husband; 'boyfriend', defined as regular non-paying male sexual partner; 'casual partner', defined as non-regular non-paying male sexual partner other than husband or boyfriend; 'paying partner', defined as male partner other than husband, boyfriend or casual partner who had sex in exchange for money or gift), sexual practices with husband (ever and in last 30 days) and other partners (in last three months), STI-related knowledge/symptoms and HIV/AIDS-related knowledge. Structured questionnaires in English were translated into local language of the participants, which was pilot-tested and revised. Each question was recorded in female voice and saved as digital sound file. The recording included the text, valid responses, and instructions to the participants that were played for each new question, which the participants could hear through headphones. Response categories were linked to a unique colour that was displayed on a specific alphabet/symbol button on the keyboard, using coloured stickers. The screen in the C-ACASI displayed the question ID and the colour-coded valid response bars (for categorical responses) or a blank box (for numeric responses). Neither the question nor the response texts were displayed on the screen to further ensure privacy and confidentiality for the participants. Only participant ID number, current date and time, together with "NEXT" and "PREVIOUS" arrow buttons to navigate to the next or previous questions were displayed. The participants were able to replay the question and valid responses by pressing a button on the keyboard, marked as "headphone". The entry of a response was marked by the change in the colour of the corresponding response bar on the screen to grey, along with a "beep" sound.

We selected three local female interviewers, who were trained to handle C-ACASI software on laptop computers. The interviewers approached the participants at their households and administered the interviews in the participants' homes or another place convenient to the participants. Participants were instructed on the use of the laptop computer and to complete the C-ACASI practice module, after which they themselves were able to use the system unassisted. The interviewers were available to clarify any questions and, if needed, to assist in using C-ACASI.

\subsection{Ethics statement}

The interviewers obtained written informed consent from the study participants. The study procedures were approved by the Institutional Ethics Committee of National Institute of Epidemiology, ICMR, Chennai.

\subsection{Data analysis}

We calculated proportions for socio-demographic and behaviour characteristics. We calculated the odds ratio with $95 \% \mathrm{CI}$, for selected exposure of young women among users and nonusers of condom during last sex with husband and boyfriend, separately. We used multiple logistic regression to calculate the adjusted odds ratio and 95\% CI for variables with $p$-value $<0.05$ in univariate analysis. Analysis of data was done using EpiInfo version 3.5.3. 


\section{Results}

\subsection{Socio-demographic characteristics}

Of the 250 young women, 127 (50.8\%) were 18-20 years old, 230 (92\%) were educated up to standard nine and above, 206 (82.4\%) were Christians, 191 (76.4\%) were students, 50 (20\%) were married and 37 (14.8\%) lived with their partner or husband.

\subsection{Sexual behaviour}

Of the 250 women, 152 (60.8\%) reported ever having sex, of whom 102 (67\%) were not married. In all 50 (20\%) women were currently married, 46 (18.4\%) reported currently having a boyfriend, 10 (4\%) reported ever having a casual male partner and $8(3.2 \%)$ reported having sex in exchange for money. These were not mutually exclusive. The mean age at first sex of 152 respondents was 18 years (standard deviation 2.2). Of the 200 unmarried and 50 married women 102 (51\%) and 32 (64\%), respectively, reported pre-marital sex. The mean age at marriage of 50 married women was 19 years. Married women reported engaging in sexual intercourse with husband on an average 7.5 times in past one month (range 4-10 times). Twenty-four of 50 (48\%) married women reported alcohol use by husband before sexual intercourse. Ever practicing anal sex with husband was reported by four (8\%) of 50 married women. Among the 46 young women who currently had a boyfriend, the median duration of such relationships was 3.5 months (range 1-12). The average frequency of sexual intercourse with boyfriend was 2.6 times in last month (range 1-4 times). Eight (18.6\%) of 43 women reported to have ever had anal sex with their boyfriend. Having sex for money was reported by 8 (3.2\%) of 250 young women at the mean age of 19 years. None of the women reported having a casual or paying sexual partner in the last three months.

\subsection{Condom use}

Sixteen (32\%) of 50 married women reported condom use during last sexual intercourse with husband. The decision to use condom was taken by both wife and husband according to 37 (74\%) of 50 married women. Among them, 16\% reported using condom most of the times, $32 \%$ sometimes and $52 \%$ never. Among 43 respondents who did not use condom most of the times 23 (53.3\%) did not know where to get one and $21(42 \%)$ were of the opinion that condom was not necessary with husband. Condom use during last sexual intercourse with their boyfriend was reported by 17 (37.8\%) of 45 women. Among women with boyfriends, 33 (86.6\%) of 38 respondents felt that condom was not necessary and 20 (55.6\%) of 36 women or their partner did not like using condom (Table 1).

\subsection{STI- and HIV-related characteristics}

Of the 250 women, 189 (76\%) had ever heard about STIs, and only $5(2 \%)$ could describe all the six symptoms of STI among women. Overall, 161 (64\%) of 250 reported having suffered
Table 1 - Condom use among young women, Tura town, Meghalaya 2014.

\begin{tabular}{|c|c|c|c|}
\hline Characteristics & $n$ & $N$ & $\%$ \\
\hline \multicolumn{4}{|l|}{ Condom use with husband } \\
\hline Condom use during last sex & 16 & 50 & 32 \\
\hline \multicolumn{4}{|c|}{ Opinion about condom use during sex with husband } \\
\hline Don't know where to get & 23 & 43 & 53.3 \\
\hline Not necessary with husband & 21 & 44 & 42.9 \\
\hline Husband does not like using condom & 16 & 43 & 37.2 \\
\hline Don't like using condom & 14 & 44 & 28.6 \\
\hline Condom reduces pleasure & 14 & 44 & 28.6 \\
\hline Condom costly & 11 & 43 & 25.5 \\
\hline \multicolumn{4}{|l|}{ Condom use with other partners } \\
\hline Condom use during last sex with boyfriend & 17 & 45 & 37.8 \\
\hline \multicolumn{4}{|c|}{ Opinion about condom use during sex with boyfriend } \\
\hline Condom not necessary & 33 & 38 & 86.6 \\
\hline Don't like using condom & 20 & 36 & 55.6 \\
\hline Partner does not like & 20 & 36 & 55.6 \\
\hline Don't know where to get & 21 & 39 & 53.8 \\
\hline Condom reduces pleasure & 14 & 34 & 41.4 \\
\hline Condom costly & 6 & 35 & 17.1 \\
\hline
\end{tabular}

from any STI symptoms in the last twelve months. Lower abdominal pain and itching in the genital area were reported by $104(43.3 \%)$ and 62 (26\%) of 240 respondents, respectively, while 45 (18.3\%) of 246 respondents reported burning micturition in the last twelve months. Two hundred and two (81\%) of 250 women had ever heard about HIV/AIDS and 124 (50\%) of 247 respondents knew that HIV could be prevented. Only 11 (4\%) of 250 women correctly answered all questions on ways to prevent HIV infection. In all, 141 (56\%) women knew that healthy-looking individuals could be infected with HIV, 50 (20\%) had heard of anti-retroviral therapy, 87 (35\%) knew someone infected with HIV, and 187 (75\%) knew about motherto-child transmission of HIV. Twenty-eight (11\%) of 250 women had undergone HIV testing in the past.

\subsection{Factors associated with condom use}

Condom use during last sex with husband was independently associated with the women's age between 18 and 20 years (OR 3.6, 95\% CI 1.0-13.6), occupation as student (OR 49.4, 95\% CI 17.7-137.7) and teacher (OR 20.4, 95\% CI 4.9-84.8), and knowledge that HIV can be prevented (adjusted OR 4.1, 95\% CI 1.03-16.3) (Table 2). We did not find any factors to be significantly associated with condom use during last sex with boyfriend (data not shown).

\section{Discussion}

This is the first report on sexual behaviour, condom use and HIV/STI related knowledge among young urban women collected using C-ACASI from India's north-eastern state of Meghalaya. We report early sexual debut and common occurrence of pre-marital sex among young females in this area. Use of condoms with husbands and boyfriends was infrequent with moderately high reporting of anal sex. Condom use with husbands was higher among women with knowledge on HIV prevention. 
Table 2 - Selected characteristics of young women associated with condom use during last sex with husband, Tura town, Meghalaya, 2014.

\begin{tabular}{|c|c|c|c|c|c|c|c|}
\hline \multirow[t]{4}{*}{ Characteristics } & \multicolumn{4}{|c|}{ Frequency of exposure } & \multirow[t]{4}{*}{ Odds ratio } & \multirow[t]{4}{*}{$95 \% \mathrm{CI}$} & \multirow[t]{4}{*}{$p$-Value } \\
\hline & \multicolumn{4}{|c|}{$\begin{array}{c}\text { Condom use during last sex with } \\
\text { husband }\end{array}$} & & & \\
\hline & \multicolumn{2}{|c|}{ Yes $(N=16)$} & \multicolumn{2}{|c|}{ No $(N=34)$} & & & \\
\hline & $n$ & $\%$ & $n$ & $\%$ & & & \\
\hline \multicolumn{8}{|l|}{ Socio-demographics } \\
\hline Age $18-21$ years & 7 & 43.8 & 6 & 17.6 & 3.6 & $1.0-13.6$ & 0.05 \\
\hline Education up to standard 10 & 3 & 18.8 & 12 & 35.3 & 2.4 & $0.6-9.9$ & 0.19 \\
\hline Christian & 10 & 62.5 & 22 & 64.7 & 0.9 & $0.3-3.1$ & 0.56 \\
\hline \multicolumn{8}{|l|}{ Occupation } \\
\hline Students & 6 & 37.5 & 9 & 26.5 & 49.4 & $17.7-137.7$ & $<0.001$ \\
\hline Teachers/others & 2 & 12.5 & 3 & 8.8 & 20.4 & $4.9-84.8$ & $<0.001$ \\
\hline Housewife & 8 & 50.0 & 22 & 64.7 & 1 & & \\
\hline \multicolumn{8}{|l|}{ Sexual behaviour } \\
\hline \multicolumn{8}{|l|}{ Age at first sex (years) } \\
\hline $14-17$ & 1 & 6.3 & 7 & 20.6 & 1.5 & $0.5-4.6$ & 0.486 \\
\hline $18-20$ & 12 & 75.0 & 17 & 50.0 & 1.9 & $0.8-4.9$ & 0.152 \\
\hline $21-24$ & 3 & 18.8 & 10 & 29.4 & 1 & & \\
\hline Had pre-marital sex & 12 & 75.0 & 20 & 58.8 & 0.5 & $0.1-1.8$ & 0.21 \\
\hline Age at marriage $15-18$ years & 8 & 50.0 & 15 & 44.1 & 1.3 & $0.4-4.2$ & 0.46 \\
\hline Husband as decision-maker for condom use & 2 & 12.5 & 4 & 11.8 & 0.9 & $0.1-5.7$ & 0.63 \\
\hline Alcohol use by husband before sex & 6 & 37.5 & 18 & 52.9 & 0.5 & $0.2-1.8$ & 0.237 \\
\hline Alcohol use by wife before sex with husband & 2 & 12.5 & 6 & 17.6 & 0.6 & $0.1-3.6$ & 0.47 \\
\hline Ever had anal sex with husband & 2 & 12.5 & 2 & 5.9 & 2.3 & $0.3-17.9$ & 0.38 \\
\hline \multicolumn{8}{|l|}{ Knowledge on STI/HIV } \\
\hline Heard about STI & 13 & 81.3 & 19 & 55.8 & 3.1 & $0.8-13.4$ & 0.09 \\
\hline Know all symptoms of STIs in women & 1 & 6.3 & 1 & 2.9 & 2.2 & $0.1-37.6$ & 0.54 \\
\hline Any STI symptom in past 12 months & 14 & 87.5 & 25 & 73.5 & 2.5 & $0.5-13.3$ & 0.232 \\
\hline Heard about HIV & 13 & 81.3 & 23 & 67.6 & 2.1 & $0.5-8.8$ & 0.25 \\
\hline Knew about ways of HIV prevention & 8 & 50.0 & 7 & 20.6 & $3.8^{\mathrm{a}}$ & $1.1-13.9$ & 0.03 \\
\hline Knew about MTCT of HIV & 13 & 81.3 & 19 & 55.9 & 3.4 & $0.8-14.2$ & 0.07 \\
\hline Heard about ART & 2 & 12.5 & 4 & 11.8 & 1.1 & $0.2-6.6$ & 0.63 \\
\hline Knew HIV infected person & 4 & 25.0 & 8 & 23.5 & 1.1 & $0.3-4.3$ & 0.58 \\
\hline Underwent HIV testing & 6 & 37.5 & 11 & 32.4 & 1.2 & $0.4-4.3$ & 0.47 \\
\hline
\end{tabular}

A study among 15-24-year-old urban youth in Meghalaya documents that $21.8 \%$ women and $13.5 \%$ men reported ever having sex. ${ }^{8}$ Traditionally, in India, we observe a cultural silence around discussing STIs and HIV, as these are closely associated with personal sexual behaviour and stigma. Young women may rely on intimacy to fit in with social norm, in search of enjoyment. ${ }^{11}$ However, they are reluctant to discuss sexual matters due to discrimination and stigma and fear of judgemental attitude. Although two-third of the unmarried women reported ever having sexual intercourse only a fifth reported a regular partner or boyfriend. This may be because of anticipated stigma, fear of parents, and embarrassment in society. It is difficult to gather accurate information on sexual behaviour and actual burden of STI/RTI and HIV. Knowing the sexual behaviour not only gathers the information about one's sexual health but also helps in making appropriate culturespecific strategies for preventing transmission of STI and HIV. The C-ACASI used in our study created an enough private environment for the women to discuss sexual behaviour, and matters related to STI and HIV.

Our study indicated sexual debut at or before 18 years is more common in the community and pre-marital sex among the women was also common. This could create a vulnerability network among the women and enhance the spread of STI. Studies report that early sexual debut could be delayed with strong parental relationship, and supervision by the parents. ${ }^{12}$ Although our study did not explore about parental supervision among young women, who reported early sexual debut, we suggest in depth studies to explore the reasons associated with early sexual debut.

Thirteen percent of young women in our study reported engaging in anal sex with their husbands and boyfriends. These are relatively high figures considering that anal sex is highly stigmatising and illegal in India. ${ }^{13}$ In India, reported prevalence of anal sex among urban married couples ranges from $1 \%$ to $20 \% .{ }^{14}$ A study from Tamil Nadu reported that $13 \%$ truckers and their wives engaged in anal sex. ${ }^{15}$ Studies among female sex workers in India have documented the prevalence of anal sex to be $12 \%$ or higher. ${ }^{16}$ Culturally appropriate gender norms in sexual relationships often influence the sexual behaviours of women in India, such that there is a male preference in sexual practices. ${ }^{17}$ On the other hand, young people are more exposed to sexual depictions in media and pornography. They are also more open to experimentation in their sexual activities. ${ }^{18}$ It is also possible that young people may use anal sex as an alternative method to prevent 
pregnancy while not wanting to use other contraceptives including condoms. ${ }^{19}$ Heterosexual anal sex has been associated with STIs, including HIV, among both men and women. ${ }^{19}$ Information about STI risks associated with all types of sexual activities, including anal sex should become part of the awareness messages regarding safe sex practices.

Easy access to alcohol in the area is widely known. It is a cultural practice to consume alcoholic beverages during social functions and gatherings. Alcohol use by husband has been reported to increase rates of sexual transmission of STI and HIV in married women in Mumbai. Sexual acts under the influence of alcohol are reported to be associated with no or inconsistent use of condoms, having sex with multiple partners, and domestic violence, if wife refuses sex or insists on condom use. ${ }^{20}$ Frequent alcohol consumption has also been shown to be associated with heterosexual anal intercourse in Indian setting. ${ }^{21}$ It has been observed that in the north-eastern region of India, generally the young population adopt westernised values, and there is a traditionally liberal attitude towards sex and free lifestyles. This along with widespread unemployment and tribal culture of regular consumption of rice brew makes the young adults most vulnerable in adopting risky sexual behaviour. ${ }^{22}$ Although alcohol consumption is culturally ingrained in the lifestyle in Meghalaya, an indepth study on its influence on sexual behaviours and condom use and consequently on the transmission of STI and HIV among young men and women would provide greater insight into the problem in this region.

Condom offers protection against unwanted pregnancy, and STI including HIV. In our study most of the women were not aware about the importance of condom use. The practice of using condom was, therefore, quite low among them. Condom use among young adult women in urban Meghalaya has been documented to be $9 \% .{ }^{6}$ It could be due to, less or no education and unawareness about STI/HIV as reported in study done in Assam. ${ }^{3}$ A recent study documented that $27 \%$ young men and $7 \%$ of young women had ever used condom with consistent condom use reported by $13 \%$ men and 3\% women. ${ }^{5}$ The participants who used condom in this study were women, who were younger and students, while the participants who used condoms the least were 21-24-year-old married women, with stable union. Our results are consistent with study in Brazil that reported lowest condom use among the married women and most among the younger women still pursuing education. ${ }^{23}$ This could be due to a greater awareness of the risk for pregnancy or STIs among unmarried young women. Reported premarital sex was quite high among both married and unmarried women and use of condom was low. This is consistent with studies in India that document limited condom use in pre-marital or marital relationships. ${ }^{24}$ Condom use among married couples may be perceived as mistrust and infidelity and hence not common. ${ }^{25}$ It is also important to understand the cultural context of sexual behaviours and condom use among the small proportion of young married women in our study. In matrilineal societies, such as in Meghalaya, both attitude and behaviour are influenced by preference for female child. Even after reaching the desired fertility level or achieving their desired sex composition of children, majority of the women or couple do not use any contraception or condom. ${ }^{26}$ This attitude could have contributed to low usage of condom among married women in our study. Promotion of condom use among married couples will need to address the socio-cultural beliefs and perceptions related to sexual behaviour and will require longterm efforts. In this study, knowledge of HIV prevention was associated with condom use with husband but not with boyfriends. Although it provides support for continued promotion of HIV prevention messages, there is a need to intensify the same for younger women and men.

Our study had certain limitations. The participants could have had difficulty in reporting intimate experiences leading to under-estimation of certain sexual behaviours. However, confidentiality was ensured as the interviews were done using C-ACASI system. The C-ACASI allowed the participants to refuse or not respond to any questions. Hence we found several missing responses related to age at first sex, having boyfriend, extramarital partners, and condom use, as reflected in the changing denominators for these variables. This finding was similar to study conducted in economically disadvantaged urban area in Delhi. ${ }^{27}$ Temporality of the associations cannot be confirmed due to the inherent design of crosssectional study. The analyses to determine the factors associated with condom use with husband as well as boyfriends were underpowered. Study with larger sample size of married women or those with other sexual partners would definitely provide more robust and valid measure of associations.

This study indicates that young urban women in this area need comprehensive sexual education and awareness on modes of transmission of STI, including HIV. Each contact by individuals, adolescents and young adults in particular, with health professional should be taken as an opportunity to educate them on sexuality and prevention of STIs. All education messages should emphasise the role of condoms in reducing the risk of STIs, including HIV. Service delivery structure should enable them to obtain condom easily and privately. The healthcare provider systems need to consider the culture-specific context while delivering prevention messages for safe sex, including all types of sexual practices.

\section{Conflicts of interest}

The authors have none to declare.

\section{R E F E R E N C E S}

1. National AIDS Control Organization. National Guideline on Prevention, Management and Control of Reproductive Tract Infection and Sexually Transmitted Infection. New Delhi: NACO, Ministry of Health and Family Welfare, Government of India; 2007.

2. Centers for Disease Control Prevention. Sexually Transmitted Disease Surveillance 2011. Atlanta: CDC, US Department of Health and Human Services; 2012.

3. Chakraborty S, Hazarika PJ. Misconception knowledge regarding HIV/AIDS among married women in the reproductive age group in Assam, India. World Appl Sci J. 2011;15(7):966-972. 
4. Rotermann M. Trends in teen sexual behaviour and condom use. Health Rep. 2008;19(3):53-57.

5. Jejeebhoy SJ, Santhya KG. Sexual and Reproductive Health of Young People in India: A Review of Policies, Laws and Programmes. New Delhi: Population Council; 2011.

6. International Institute for Population Sciences. District Level Household and Facility Survey (DLHS-3). 2007-08-IndiaMeghalaya. Mumbai: IIPS; 2010.

7. Marak B. Description and Evaluation of Prevention, Management and Control of Reproductive Tract Infection Including Sexually Transmitted Infection, Tura, Meghalaya, 2014. Field Project Report. Chennai: ICMR School of Public Health, National Institute of Epidemiology; 2014.

8. International Institute for Population Sciences. Key Indicators for Meghalaya from NFHS-3. 2009. http://www.rchiips.org/ nfhs/pdf/Meghalaya.pdf.

9. Census of India. West Garo Hills District: Census 2011 Data. 2011. http://www.census2011.co.in/census/district/ 379-west-garo-hills.html [accessed 27.06.14].

10. Bhatnagar T, Brown J, Saravanamurthy PS, Kumar RM, Detels R. Color-Coded Audio Computer-Assisted SelfInterviews (C-ACASI) for poorly educated men and women in a semi-rural area of south India: "Good, scary and thrilling". AIDS Behav. 2013;17(6):2260-2268.

11. Ingersoll KS, Ceperich SD, Nettleman MD, Johnson BA. Risk drinking and contraception effectiveness among college women. Psychol Health. 2008;23(8):965-981.

12. Mehra S, Savithri R, Coutinho L. Sexual behaviour among unmarried adolescents in Delhi, India: opportunities despite parental controls. In: Regional Population Conference. Bangkok 2002.

13. Herget G. India: UNAIDS claims law criminalizing homosexuality hinders HIV prevention. HIV AIDS Policy Law Rev. 2006;11(1):35-36.

14. Savara M, Sridhar C. Sexual behaviour of urban educated Indian men: results of a survey. J Fam Welf. 1992;38(1):30-43.

15. Bhatnagar T, Saravanamurthy PS, Detels R. Sexual behaviors and partner-specific correlates of heterosexual anal intercourse among truck drivers and their wives in south India. Arch Sex Behav. 2015;44(2):295-306.

16. National AIDS Control Organisation. Female Sex Workers (FSWs) and their Clients - National Behavioural Surveillance
Survey. New Delhi: NACO, Ministry of Health and Family Welfare, Government of India; 2006.

17. George A. Differential perspectives of men and women in Mumbai, India on sexual relations and negotiations within marriage. Reprod Health Matters. 1998;6(12): 87-96.

18. Verma RK, Pulerwitz J, Mahendra V, et al. Challenging and changing gender attitudes among young men in Mumbai, India. Reprod Health Matters. 2006;14(28):135-143.

19. Erickson PI, Bastani R, Maxwell AE, Marcus AC, Capell FJ, Yan KX. Prevalence of anal sex among heterosexuals in California and its relationship to other AIDS risk behaviors. AIDS Educ Prev. 1995;7:477-493.

20. Berg MJ, Kremelberg D, Dwivedi P, et al. The effects of husband's alcohol consumption on married women in three low-income areas of greater Mumbai. AIDS Behav. 2010;14 (1):126-135.

21. World Health Organization. Alcohol Use and Sexual Risk Behaviour: A Cross-Cultural Study in Eight Countries. Geneva: WHO; 2005.

22. HIV/AIDS situation in North East India. 2009. http://drugfreene. wordpress.com/2009/02/02/hivaids-situation-in-north-eastindia/ [accessed 25.06.14].

23. Silveira MF, Santos IS, Béria JU, Horta BL, Tomasi E, Victora CG. Factors associated with condom use in women from an urban area in southern Brazil. Cad Saúde Pública. 2005;21 (5):1557-1564.

24. Santhya K, Acharya R, Jejeebhoy SJ. Condom use before marriage and its correlates: evidence from India. Int Perspect Sex Reprod Health. 2011;37(4):170-180.

25. Bhattacharya G. Sociocultural and behavioral contexts of condom use in heterosexual married couples in India: challenges to the HIV prevention program. Health Educ Behav. 2004;31(1):101-117.

26. Narzary PK, Sharma SM. Daughter preference and contraceptive-use in matrilineal tribal societies in Meghalaya, India. J Health Popul Nutr. 2013;31(2): 278-289.

27. Jaya. Hindin MJ, Ahmed S. Differences in young people's reports of sexual behaviors according to interview methodology: a randomized trial in India. Am J Public Health. 2008;98(1):169-174. 